\title{
Erratum to: Intravenous injection of gadobutrol in an epidemiological study group did not lead to a difference in relative signal intensities of certain brain structures after 5 years
}

Marie-Luise Kromrey ${ }^{1} \cdot$ Kim Rouven Liedtke $^{1} \cdot$ Till Ittermann $^{2}$ • Sönke Langner ${ }^{1}$ • Michael Kirsch $^{1}$ • Werner Weitschies ${ }^{3}$ • Jens-Peter Kühn ${ }^{1}$

Erratum to: Eur Radiol

DOI 10.1007/s00330-016-4418-Z

Unfortunately, the authors have discovered an error in the specified dosage of the contrast agent Gadobutrol. The correct dosage is $0.15 \mathrm{mmol} / \mathrm{kg}$ and not $1.5 \mathrm{mmol} / \mathrm{kg}$, as indicated.

The authors sincerely apologise for this error.

The online version of the original article can be found at http://dx.doi. org/10.1007/s00330-016-4418-z.

Marie-Luise Kromrey

marie-luise.kromrey@uni-greifswald.de

1 Institute of Diagnostic Radiology and Neuroradiology, University Medicine Greifswald, Ferdinand-Sauerbruch-Straße,

D-17475 Greifswald, Germany

2 Institute for Community Medicine, University Medicine Greifswald, Greifswald, Germany

3 Institute ofBiopharmacy and Pharmaceutical Technology, University Greifswald, Greifswald, Germany 